Title: Measuring PrEP Preferences Among At-Risk Military Populations: Results of an and David Vlahov, PhD, RN ${ }^{a, d}$

\title{
Authors' Affiliation:
}

a Yale School of Nursing, 400 West Campus Drive, Orange, CT 06477, United States

${ }^{\mathrm{b}}$ Loma Linda University, Griggs Hall 11065, Loma Linda, CA 92350, United States

${ }^{c}$ Yale School of Medicine, 333 Cedar Street, New Haven, CT 06510, United States

${ }^{\mathrm{d}}$ Yale School of Public Health, Department of Epidemiology-Microbial Diseases, 60 College St, New Haven, CT 06510, United States

\section{Correspondence:}

José Gutierrez, jose.gutierrez@aya.yale.edu

\section{Citation:}

Gutierrez JI, Vlahov D, et al. Measuring PrEP Preferences Among At-Risk Military Populations: Results of an Adaptive Choice Based Conjoint Analysis Study. (Under review) 
Dr. Xiao-Bing Fu, Editor-in-Chief

Dr. Qing-Jie Li, Honorary Editor-in-Chief

Military Medical Research

July 27,2020

Dear Drs. Fu and Li:

I am writing to submit our manuscript titled "Measuring PrEP Preferences Among AtRisk Military Populations: Results of an Adaptive Choice Based Conjoint Analysis Study" for consideration for publication as a research article within the Military Medical Research journal.

Pre-exposure prophylaxis (PrEP) is a medication that effectively prevents HIV infection when taken correctly yet is underutilized within the military health care system. For this study, we identified the preferred characteristics of an ideal PrEP delivery program within the military health care system through an anonymous, conjoint analysis survey of at-risk, U.S. military members. Our findings reveal that a military, on-base health care setting is most preferred for PrEP delivery, yet also indicate a need for quality clinical interactions that are sensitive to sexual identity, mental health, and decision autonomy.

Given the low uptake of PrEP by at-risk military members, we believe that the findings presented in our paper will appeal to key infectious disease stakeholders and policymakers who subscribe to Military Medical Research. Our results will allow your readers to understand which characteristics of a military PrEP delivery program are most attractive to the distinct preferences of this vulnerable population. In doing so, we hope our research will advance evidence-informed PrEP delivery programs within the military health care system tailored to the preferences of U.S. military members most at risk for acquiring HIV.

All listed authors confirm that this manuscript has not been previously published, nor is it currently under consideration by any other journal. Furthermore, all authors have approved the contents of this paper and have agreed to MMR's submission policies.

Should our manuscript be selected for peer review, we would like to suggest the following reviewers that would be able to objectively evaluate our findings and interpretation based on their research background and expertise.

- Liana Fraenkel, MD, MPH, Yale University/Berkshire Medical Center, liana.fraenkel@yale.edu (expertise: conjoint analysis, decision science, preference behavior)

- José A. Bauermeister, PhD, MPH, University of Pennsylvania, bjose@upenn.edu (expertise: HIV/AIDS \& PrEP science, health-seeking \& sexual behaviors of at-risk populations)

- Patrick W. Kelley, MD, DrPH, Fairfield University, pkelley@fairfield.edu (expertise: military preventative medicine, global infectious disease control) 
- Jason F. Okulicz, MD, Uniformed Services University of the Health Sciences/U.S. Air Force HIV Medical Evaluation Unit, jason.f.okulicz.mil@mail.mil (expertise: infectious diseases and PrEP use among military populations)

Each of the authors named on the manuscript has contributed to the development, interpretation and drafting of this manuscript. To the best of our knowledge, the named authors have no conflicts of interest.

Sincerely,

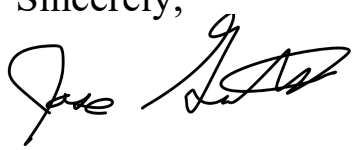

\section{José I Gutierrez Jr., PhD, FNP-BC}

Yale University, School of Nursing

E: jose.gutierrez@aya.yale.edu

T: 309-335-4242

Additional Contact Information:

Attn: José I Gutierrez Jr., PhD, FNP-BC

Fellow, National Clinician Scholars Program

University of California, San Francisco

E: jose.gutierrez2@ucsf.edu

T: 309-335-4242 


\section{ABSTRACT}

49 BACKGROUND. Pre-exposure prophylaxis (PrEP) effectively prevents HIV infection,

50 yet its uptake remains low among U.S. military men who have sex with men (MSM).

51 Research shows that health services matching preferences produce favorable outcomes.

52 Therefore, an early step for planning program design is to characterize and identify

53 preferences for improved PrEP delivery within this population.

54 METHODS. HIV-negative military MSM were recruited through a closed, LGBT

55 military social media group. Participants completed an anonymous survey presenting five

56 experimentally varied attributes of interest related to PrEP administration (dosing

57 method, provider type, visit location, lab work evaluation location, and dispensing

58 venue). Relative importance and part-worth utility scores were generated using

59 Hierarchical Bayes (HB) estimation, and the randomized first choice model was used to

60 examine participation interest across eight possible PrEP program scenarios.

61 RESULTS. Among the 429 participants and the eight scenarios that varied the five

62 attributes into delivery profiles, the most preferred scenario (69.9\%) featured a daily pill

63 or long-term PrEP injection, military provider, smartphone/telehealth visit, lab evaluation

64 on-base, and on-base medication pick-up. Responses indicated the need for providers to

65 familiarize themselves with PrEP prescription knowledge and to provide interactions

66 sensitive to sexual identity, mental health, and decision autonomy.

67 CONCLUSION: These results suggest that a military setting is preferred over a civilian

68 or off-site one, yet more importantly, it points to a high value placed on the quality of

69 clinical interactions. High interest in long-acting implants and injections also suggest

70 potential markets for future PrEP engagement. 
71 TRIAL REGISTRATION. Not applicable.

72 KEYWORDS. Conjoint analysis, pre-exposure prophylaxis, PrEP, preference, decision

73 science, HIV, military health, infectious disease

74

75

76

77

78

79

80

81

82

83

84

85

86

87

88

89

90

91

92

93 


\section{BACKGROUND}

95 Each year, there are approximately 350 new cases of human immunodeficiency

96 virus (HIV) infections within members of the U.S. military; with those most affected

97 being younger, Black, and men who have sex with men.(1-5) When taken correctly, Pre-

98 exposure Prophylaxis (PrEP) effectively prevents HIV infection,(6-9) yet the current

99 PrEP cascade within the U.S. military suggests sub-optimal uptake; with an estimated

$10016 \%$ of eligible members taking PrEP and members of color remaining under-represented

101 in terms of treatment.(2) Identifying the factors that drive uptake within this population

102 remains a priority.

103 The field of PrEP science has explored multiple avenues of PrEP access

104 pathways, delivery mechanisms, and dosing methods to circumvent the geographic,

105 psychological, and adherence barriers that exist and impede PrEP engagement.(10-17)

106 Currently, military PrEP engagement depends on geographic proximity to a large medical

107 facility with specialty services, as evidenced by $41 \%$ of all military PrEP prescriptions

108 originating from military medical centers in three locations in the U.S. Additionally, $60 \%$

109 of all military PrEP prescriptions occur only after consultation with an infectious disease

110 specialist.(2) Data are sparse on military MSM's most preferred program characteristics

111 within a PrEP delivery program.

112 Health services designed around preferences in terms of product type, delivery

113 method, and location settings have been shown to produce improved treatment outcomes

114 and retention to care.(18-20) Stated preference methods, such as conjoint analysis,

115 quantify preference data of new market entrants and product characteristics; also called

116 attributes.(15, 16, 21-25) The central theory of conjoint analysis is that products or 
117 programs are viewed as a composition of various attributes that possess a certain amount

118 of value (part-worth utility score) determined by preference. By quantifying this value

119 (part-worth utility scores) for preferred attributes, these scores can then be entered into

120 market simulation models to predict how respondents might respond to any potential

121 combination of attribute levels. $(15,16,21-25)$ Using conjoint analysis, the purpose of

122 this study was to identify the preference factors that are most influential to at-risk U.S.

123 military MSM's decision to take PrEP within the military healthcare system.

\section{METHODS}

125 A convenience sample of self-reported HIV-negative, U.S. military MSM and

126 trans-individuals were recruited between March and April 2020 through a closed

127 Facebook group with an internal membership of over 7,000 LGBT U.S. military

128 members. The group administrators placed monthly advertisements describing the study

129 on the group's main forum. Those interested could click on a link to access an online

130 study disclosure form with a 'click to consent' procedure. An option to provide an e-mail

131 address that was not linked to survey responses was offered to participants who opted to

132 receive $\$ 5$ compensation for questionnaire completion. The study was approved by the

133 Yale University Institutional Review Board.

134 To collect and quantify respondent preference data, an adaptive choice-based

135 conjoint (ACBC) survey instrument was developed based on a review of the literature

136 and in-depth input from PrEP experts and U.S. military MSM.(2-5, 10, 11, 13, 14, 26-

137 35).(36-38) With a focus on modifiable PrEP program characteristics, the final survey

138 design was composed of five different PrEP program delivery attributes of interest that

139 included: dosing method (daily pill, on-demand pill regimen [two pills before sex, one 
140 pill for two days after], rectal douche [before sex], injection [every 2 months], implant

141 [once a year]), provider type (military, civilian), visit location (on-base, off-base,

142 smartphone app), dispensing venue (on-base, off-base, mail delivery), and lab

143 evaluation (on-base, off-base, home-based mail kit). The survey was piloted with 11

144 members within the targeted social media group for concept testing, and the descriptions

145 and wording of three attribute categories and two attribute level choices were revised for

146 clarification based on feedback. Additionally, we collected demographical data to include

147 age, race, ethnicity, rank type (officer, enlisted or warrant officer), military branch,

148 geographic region, PHQ2(39) and HIRI-MSM risk score,(40) as well as measures to

149 explore levels of disclosure discomfort and anticipated stigma within interactions with a

150 health care provider.

151 ANALYSIS

152 The final survey instrument was loaded into Lighthouse Studio 9, and an

153 experimental design module was used to pre-test the design with 500 simulated

154 respondents for optimal choice task configuration. The final design produced a survey

155 where each level within an attribute was seen at least three times per respondent;

156 achieving a high degree of precision at the individual level with a standard of error of

$157<0.03$ and all efficiencies reporting at 1.00.(41)

158 Table 1 displays the CONSORT diagram of respondent enrollment and exclusion.

159 To ensure the integrity of the data and eliminate random or duplicate responders, security

160 features within the Sawtooth software and servers recognize returning study participants

161 through the use of internet browser cookies and IP addresses. It also prevents repeated or

162 duplicate attempts to retake the survey.(42) Additionally, as extensive pilot testing 
163 required at least 10 to 15 minutes, responses completed in less than 10 minutes (or if a

164 respondent selected the same answer for all items) were excluded. Also, the root

165 likelihood (RLH) fit statistic for each respondent was analyzed to evaluate within-

166 respondent choice consistency. RLH, which has a probability value from 0 to 1.0 , was

167 used to discriminate between respondents who answered choice-questions consistently or

168 randomly.(43) The survey design was tested by 1,000 computer-generated mock

169 respondents to determine the median RLH for 'random responders' at the 95\% percentile

170 (0.5178 RLH). Survey respondents with an RLH below this score were excluded, as the

171 inclusion of 'random responders' can affect the calculation of preference scores and

172 participation rates.(43)

173 For conjoint analyses, the Hierarchical Bayes (HB) procedure was used to

174 estimate part-worth utility scores (PWUS) on an individual level for its accuracy and

175 efficiency, $(44,45)$ and was used to analyze the PWUS of the aggregated sample across

176 all 16 attribute levels. The resulting PWUS of the levels under each attribute category are

177 zero-centered; meaning that the sum of the level scores under each attribute category

178 equal to zero. Scores that are further away from zero (0) indicate a stronger positive or

179 negative preference for the level choice in relation to the other level choices under the

180 same attribute. $(38,41,45)$ After identifying each attribute level PWUS, the attribute

181 relative importance scores (RIS) can then be calculated to characterize the magnitude of

182 influence that each attribute category has on the respondents preference decision-making.

183 The RIS for this study was calculated by dividing the range of PWUS for levels under

184 each attribute by the sum of the ranges, and then multiplying by $100 .(46,47)$ Therefore,

185 if an attribute RIS is $45 \%$, then this means that $45 \%$ of an individual's decision making 
186 for product engagement will be influenced by preferences within that attribute category.

187 The PWUS were then used to predict the rate of participation among eight hypothetical

188 PrEP program scenarios. PrEP program scenarios were configured after a variety of

189 currently available or currently feasible PrEP program models, as well as best- and worst-

190 case scenarios based on the highest and lowest PWUS among the attribute levels. For the

191 aggregate sample, participation rates for these PrEP scenarios were generated using the

192 randomized first choice model; in which PWUS are summed across the levels

193 corresponding to each option, and then exponentiated and rescaled, so they sum to

194 100.(46,47) This approach is based on the assumption that respondents or consumers

195 will prefer a product with the highest composite utility (or value) adjusting for both

196 attribute and program variability.(46) The randomized choice model accounts for

197 variation in each participant's total utility for each option and error in point estimates of

198 the utility, and has been shown to have better predictive ability than other shares of

199 preference models.(47) All data analyses were performed using XLSTAT and Sawtooth

200 Lighthouse Studio 9.0.

201 RESULTS

202 Participants. Table 2 shows the descriptive statistics of the 429 respondents that

203 met the required elapsed survey time and RLH consistency cut-off. Overall, mean age

204 was 30 years old, $96.7 \%$ identified as cis-gendered male (2.6\% identified as trans-female,

205 and $0.7 \%$ identified as trans-male), $72 \%$ were white, $72.5 \%$ were of non-Hispanic

206 ethnicity, 46.4\% were of officer rank, 54.1\% had at least a bachelor's degree or above,

207 and 48.7\% were within the U.S. Army branch. Overall, 62.7\% screened positive for 
208 depressive symptoms, $89.3 \%$ were defined as having a high objective risk for acquiring

$209 \mathrm{HIV},(40)$ and $83.0 \%$ reported condomless receptive anal sex within the prior six months.

210 In interactions with their primary care provider (PCP), 36.8\% were "somewhat-"

211 or "extremely" uncomfortable with talking about sex with their PCP, 48.1\% were

212 "somewhat" or "very" fearful of being judged by their PCP for their gay/MSM identity,

213 and $45.2 \%$ were fearful for becoming mistreated by their PCP for their gay/MSM identity

214 as well. Furthermore, $64.1 \%$ of respondents found it "somewhat" or "very" important that

215 their PCP affirms or show interest in the participant's sexual identity concerning their

216 care, and $78.4 \%$ of members found it important that their PCP provides a high degree of

217 medication decision-making autonomy for taking PrEP.

218 Table 3 shows the relative importance scores (RIS) of the five attributes, and

219 Table 4 shows the part-worth utility scores (zero-centered) for each attribute level. For

220 this study, the dosing method was the most critical attribute among the participants with a

221 relative importance score (RIS) of 45.2\%; suggesting that the participant's decision-

222 making process to participate in a PrEP program is most influenced by the level choice

223 within the dosing method attribute. For dosing method, a daily pill was the most preferred

224 option, although the bi-monthly PrEP injection and yearly implant were also preferred to

225 a slightly lesser degree. The on-demand pill regimen and before-sex rectal PrEP douche

226 were less preferred within the aggregate sample.

227 The provider type attribute was the second most important attribute to

228 respondents, although to a much lesser degree at 15.8\% (RIS). Looking at level within

229 this attribute, there was a higher preference for a military than a civilian healthcare

230 provider. The PrEP visit location attribute was the third most important attribute 
231 (RIS=14.5\%). Respondents preferred to have a virtual medical visit through a smartphone

232 app or on-base location more than an off-base visit location the most. For the laboratory

233 evaluation location attribute (RIS=13.4\%), participants preferred to provide specimens

234 for assays to initiate or continue PrEP on-base rather than a location off-base, or through

235 a self-collected, home-based mail-in kit. PrEP dispensing venue had the least influence

236 on participants' decision-making (RIS=11.0\%), with participants preferring to receive or

237 pick-up their PrEP medication on-base over a mail delivery service or a location off-base.

238 We utilized the randomized first choice model to estimate the participation

239 interest rate that individuals would have towards a variety of hypothetical PrEP program

240 configurations.(47) For this study, the relative importance and part-worth utility scores

241 were used to construct eight PrEP program scenarios for currently available or feasible

242 PrEP program models (Scenarios 1 through 5), and hypothetical PrEP program models

243 for dosing methods still in development at the time of the survey (i.e., PrEP injection,

244 implant, rectal douche) (Scenarios 6 through 8).

245 Table 4 describes the eight PrEP program scenarios and displays the rates of

246 participation interest across the individual PrEP program configurations. These same

247 eight scenarios are also referenced in Tables 5 and 6.

$248 \quad$ Scenario 1 and 2 represent on-base military PrEP delivery. Scenario 1 (Standard

249 Military Daily Pill) best represents the current state of an on-base, daily pill PrEP

250 program within the military healthcare system today; scoring a total participation rate of

$25166.4 \%$ for the aggregate sample. Scenario 2 (Standard Military Daily Pill + Smartphone)

252 utilized the smartphone app option within the current daily pill military PrEP program;

253 resulting in a $3 \%$ increase in projected participation to a total of $69.6 \%$. 
255 regimen within a best-case military setting (military provider, smartphone app visit, on-

256 base location for lab work, and on-base location to receive PrEP medication); resulting in

257 a 67.6\% participation rate. Scenario 4 (Military Home-Based PrEP) is a distance-based

258 program configured for military members whose personal or work-related circumstances

259 compel the individual to see a military provider via a smartphone app and mail-delivery

260 options; resulting in a participation rate of $65.2 \%$ among the total sample.

261 Scenario 5 (Standard Civilian Daily Pill) was configured to represent a civilian-

262 equivalent, off-base, daily pill PrEP program that circumvents the military and on-base

263 aspects of a PrEP program; with $57.7 \%$ of the aggregate sample interested in such a

264 program.

265 Scenarios 6 through 8 (Best Case Military Injection, Best Case Military Implant,

266 Best Case Military Rectal Douche, respectively) are hypothetical scenarios that utilize

267 conceptual PrEP dosing methods currently in development.(10, 14) By presenting each of

268 these dosing methods within a best-case delivery scenario (military provider, smartphone

269 app visit, on-base location for lab work, and on-base location to receive medication),

270 respondents reported a higher participation rate of $69.6 \%$ for Scenario 6 (Best Case

271 Military Injection) and 68.5\% for Scenario 7 (Best Case Military Implant). Conversely,

272 Scenario 8 (Best Case Military Rectal Douche) scored the lowest participation rate of all

273 scenarios at $51.6 \%$.

274 DISCUSSION

275 The significant findings from this study reveal that respondents prefer the 276 convenience of daily pill PrEP services on-base over civilian and off-base settings, yet 
277 also indicate a priority to address MSM-specific needs in the context of their care.

278 Despite an overall willingness to disclose same-sex activity, almost half of respondents

279 were fearful of being judged or mistreated by their PCP for their gay/MSM identity.

280 Additionally, over half of the respondents had a positive screening score for depressive

281 symptoms, and the majority of members engage in risk behaviors that categorize them as

282 having a high risk for acquiring HIV. With a growing body of literature suggesting a link

283 between depression and sexual risk behaviors among MSM,(48-50) it may be beneficial

284 for healthcare providers to provide PrEP clinics that are sensitive and inclusive to sexual

285 identity and to remain vigilant to address factors related to mental and sexual health. Also

286 important to members is valuing a high level of medication decision-making autonomy

287 for taking PrEP. Thus, healthcare providers' efforts to offer military members with the

288 necessary information and support about PrEP medication, without pressuring the

289 member into making a specific choice, may enhance the interaction experience for an

290 individual seeking PrEP within the military healthcare setting.

291 Results of the conjoint experiment found the dosing method attribute to be the

292 most critical and influential preference factor within a PrEP delivery program. The strong

293 preference for a daily pill (and when available, the PrEP injection and PrEP implant)

294 suggests that a demand remains for alternative short and long-acting PrEP methods

295 within this population. The apparent benefit to long-acting agents is that it lifts the burden

296 of a daily pill from a user; an advantage for an individual with adherence concerns or an

297 unpredictable work schedule. Military service's expeditionary nature often entails

298 military members to relocate, deploy, or miss regular follow-up appointments due to

299 specific duties. $(51,52)$ Therefore, the availability of alternative PrEP modalities that can 
300 sustain a protective level of medication with fewer, longer medication administrations

301 may be an attractive component for members interested in PrEP. While not as important

302 as the dosing methods, respondents additionally preferred seeing a military provider,

303 interacting through a smartphone telehealth visit, and utilizing on-base locations for

304 laboratory evaluation and medication pick-up.

305 A preference to see a military provider for PrEP services remains prevalent

306 among the total sample; suggesting that it is the military healthcare provider that will be

307 central to the success of a military PrEP program. In a survey of military health care

308 providers regarding PrEP knowledge and prescription habits, $49 \%$ of them rated their

309 knowledge as poor and only $29 \%$ had ever prescribed it. Additionally, $60 \%$ of members

310 received their PrEP prescription after seeing an infectious disease specialist;(2)

311 suggesting that military primary care providers may not feel comfortable prescribing

312 PrEP or may be referring members to specialists for PrEP services. Therefore, supporting

313 primary care providers with the necessary training and resources to comfortably prescribe

314 PrEP may help members engage in services; particularly since it's been shown that an

315 increase in PrEP knowledge has been associated with an increase in prescribing

316 habits.(53)

317 This study has limitations. First, this study utilized self-report measures from a

318 convenience sample recruited from an online social media group comprised of U.S.

319 military members who identify as LGBT. While there was no way to verify actual

320 eligibility for inclusion/exclusion criteria due to the anonymous nature of the survey, the

321 literature examining MSM recruitment via online methods versus in-person had found

322 similar samples of HIV/STI prevalence and HIV-testing patterns among MSM.(54, 55) 
323 However, these findings may not be generalizable to at-risk military members who do not

324 identify as being MSM or LGBT. Additionally, while quantifying preferences does not

325 guarantee intention or ultimately behavior, it can be an innovative first step and provide a

326 foundation to successfully inform PrEP initiatives.

\section{CONCLUSION}

328 This study provides an initial description of the preferences and interest for PrEP

329 by U.S. military service members with a high risk of acquiring HIV. Our results indicate

330 that PrEP interest among this population is most likely to be successful when PrEP is

331 offered as a daily pill, injection, or implant, with a medical visit performed with a

332 military healthcare provider through a telehealth smartphone app. Additionally, allowing

333 on-base locations to provide laboratory samples and to receive PrEP medication can also

334 facilitate program preference. PrEP engagement will further be enhanced by ensuring

335 that medical providers and facilities are knowledgeable and comfortable prescribing PrEP

336 services. Offering an affirming environment sensitive to health care concerns related to

337 mental and sexual health will also be important, as well as provide participants the

338 decision autonomy to take PrEP without pressure. Consequently, key populations,

339 stakeholders, and policymakers will be better equipped for scale-up of PrEP among at-

340 risk populations within the U.S. military.

341 ACKNOWLEDGEMENTS

342 The authors would like to acknowledge Carmen Portillo and Nancy R. Reynolds

343 for their contributions to this manuscript. Research reported in this publication was

344 supported by F31 grant number 1F31NR018620-01A1 by the National Institute of

345 Nursing Research (NINR). 
347 LIST OF ABBREVIATIONS

348 PrEP (Pre-exposure prophylaxis), MSM (men who have sex with men), HIV (human

349 immunodeficiency virus), LGBT (lesbian, gay, bi \& transgender), HB (Hierarchical

350 Bayes), ACBC (adaptive choice-based conjoint), PHQ2 (Patient Health Questionnaire-2),

351 HIRI-MSM (HIV Incidence Risk Index for men who have sex with men), CONSORT

352 (Consolidated Standards of Reporting Trials), IP (internet protocol), RLH (root

353 likelihood), PWUS (part-worth utility scores), RIS (relative importance score), PCP

354 (primary care provider)

355

356

357

358

359

360

361

362

363

364

365

366

367

368

369

370

371

372

373

374

375

376

377

378

379

380

381

382 
384 ETHICS APPROVAL \& CONSENT TO PARTICIPATE. The study was approved

385 by the Yale University Institutional Review Board (IRB Protocol ID: 2000024612).

386 Social media group administrators placed monthly advertisement links describing the

387 study on the group's main forum. Interested participants could click on a link to access an

388 online study disclosure form with a 'click to consent' procedure.

389 CONSENT FOR PUBLICATION. Not applicable.

390 AVAILABILITY OF DATA \& MATERIALS. The datasets used and/or analyzed

391 during the current study are available from the corresponding author on reasonable 392 request.

393 COMPETING INTERESTS. The authors declare that they have no competing interests.

394 FUNDING. Research reported in this publication was supported by the National Institute

395 of Nursing Research (NINR), under award number 1F31NR018620-01A1. Its contents

396 are solely the responsibility of the authors and do not necessarily represent the official

397 view of NIH.

398 AUTHORS CONTRIBUTIONS. JG, AD, and FA analyzed and interpreted the

399 preference data regarding PrEP delivery program preferences, as well as demographical

400 descriptive statistics. JG and DV were major contributors in writing the manuscript. All

401 authors read and approved the final manuscript.

402 ACKNOWLEDGEMENTS. The authors would like to acknowledge Carmen Portillo 403 and Nancy R. Reynolds for their contributions to this manuscript. 


\section{REFERENCES}

1. Armed Forces Health Surveillance B. Update: Routine screening for antibodies to human immunodeficiency virus, civilian applicants for U.S. military service and U.S. Armed Forces, active and reserve components, January 2013-June 2018. MSMR. 2018;25(9):2-8.

2. Blaylock JM, Hakre S, Okulicz JF, Garges E, Wilson K, Lay J, et al. HIV Preexposure Prophylaxis in the U.S. Military Services - 2014-2016. MMWR Morb Mortal Wkly Rep. 2018;67(20):569-74.

3. Hakre S, Scoville SL, Pacha LA, Peel SA, Kim JH, Michael NL, et al. Brief Report: Sexual Risk Behaviors of HIV Seroconverters in the US Army, 20122014. J Acquir Immune Defic Syndr. 2015;70(4):456-61.

4. Patterson SB, Rivera D, Sunil TS, Okulicz JF. Evaluation of extragenital screening for gonorrhea and chlamydia in HIV-infected active duty Air Force members. MSMR. 2014;21(11):7-9.

5. Hakre S, Mydlarz DG, Dawson P, Danaher PJ, Gould PL, Witkop CT, et al. Epidemiology of HIV among US Air Force Military Personnel, 1996-2011. PLoS One. 2015;10(5):e0126700.

6. Thigpen MC, Kebaabetswe PM, Paxton LA, Smith DK, Rose CE, Segolodi TM, et al. Antiretroviral preexposure prophylaxis for heterosexual HIV transmission in Botswana. N Engl J Med. 2012;367(5):423-34.

7. Grant RM, Lama JR, Anderson PL, McMahan V, Liu AY, Vargas L, et al. Preexposure chemoprophylaxis for HIV prevention in men who have sex with men. N Engl J Med. 2010;363(27):2587-99.

8. Choopanya K, Martin M, Suntharasamai P, Sangkum U, Mock PA, Leethochawalit M, et al. Antiretroviral prophylaxis for HIV infection in injecting drug users in Bangkok, Thailand (the Bangkok Tenofovir Study): a randomised, double-blind, placebo-controlled phase 3 trial. Lancet. 2013;381(9883):2083-90.

9. Baeten JM, Donnell D, Ndase P, Mugo NR, Campbell JD, Wangisi J, et al. Antiretroviral prophylaxis for HIV prevention in heterosexual men and women. N Engl J Med. 2012;367(5):399-410.

10. Lykins WR, Luecke E, Johengen D, van der Straten A, Desai TA. Long acting systemic HIV pre-exposure prophylaxis: an examination of the field. Drug Deliv Transl Res. 2017;7(6):805-16.

11. Molina JM, Charreau I, Spire B, Cotte L, Chas J, Capitant C, et al. Efficacy, safety, and effect on sexual behaviour of on-demand pre-exposure prophylaxis for HIV in men who have sex with men: an observational cohort study. Lancet HIV. 2017;4(9):e402-e10.

12. Antoni G, Tremblay C, Delaugerre C, Charreau I, Cua E, Rojas Castro D, et al. On-demand pre-exposure prophylaxis with tenofovir disoproxil fumarate plus emtricitabine among men who have sex with men with less frequent sexual intercourse: a post-hoc analysis of the ANRS IPERGAY trial. Lancet HIV. 2020;7(2):e113-e20.

13. Pines HA, Gorbach PM, Weiss RE, Hess K, Murphy R, Saunders T, et al. Acceptability of potential rectal microbicide delivery systems for HIV prevention: a randomized crossover trial. AIDS Behav. 2013;17(3):1002-15. 
14. Hendrix CW. HIV Antiretroviral Pre-Exposure Prophylaxis: Development

15. Dubov A, Fraenkel L, Yorick R, Ogunbajo A, Altice FL. Strategies to Implement Pre-exposure Prophylaxis with Men Who Have Sex with Men in Ukraine. AIDS Behav. 2018;22(4):1100-12.

16. Dubov A, Ogunbajo A, Altice FL, Fraenkel L. Optimizing access to PrEP based on MSM preferences: results of a discrete choice experiment. AIDS Care. 2018:19.

17. Touger R, Wood BR. A Review of Telehealth Innovations for HIV Pre-Exposure Prophylaxis (PrEP). Current HIV/AIDS Reports. 2019;16(1):113-9.

18. Swift JK, Callahan JL. The Impact of Client Treatment Preferences on Outcome: A Meta-Analysis. J Clin Psychol. 2009;65(4):368-81.

19. Adamson SJ, Bland JM, Hay EM, Johnson RE, Jones GT, Kitchener H, et al. Patients' preferences within randomised trials: systematic review and patient level meta-analysis. Bmj-Brit Med J. 2008;337.

20. Graff FS, Morgan TJ, Epstein EE, McCrady BS, Cook SM, Jensen NK, et al. Engagement and Retention in Outpatient Alcoholism Treatment for Women. Am J Addiction. 2009;18(4):277-88.

21. Ryan M, Farrar S. Using conjoint analysis to elicit preferences for health care. BMJ. 2000;320(7248):1530-3.

22. Phillips KA, Maddala T, Johnson FR. Measuring preferences for health care interventions using conjoint analysis: an application to HIV testing. Health Serv Res. 2002;37(6):1681-705.

23. Viney R, Lancsar E, Louviere J. Discrete choice experiments to measure consumer preferences for health and healthcare. Expert Rev Pharmacoecon Outcomes Res. 2002;2(4):319-26.

24. Lancsar E, Louviere J. Conducting discrete choice experiments to inform healthcare decision making: a user's guide. Pharmacoeconomics. 2008;26(8):66177.

25. Opuni M, Bishai D, Gray GE, McIntyre JA, Martinson NA. Preferences for characteristics of antiretroviral therapy provision in Johannesburg, South Africa: results of a conjoint analysis. AIDS Behav. 2010;14(4):807-15.

26. Anderson CW, Smith HR. Stigma and honor: Gay, lesbian, and bisexual people in the US military. Homosexual issues in the workplace. 1993:65-89.

27. Biddix JM, Fogel CI, Perry Black B. Comfort levels of active duty gay/bisexual male service members in the military healthcare system. Mil Med. 2013;178(12):1335-40.

28. Russell TG. An examination of stigma in the military. 2013.

29. Lloyd J, Papworth E, Grant L, Beyrer C, Baral S. Systematic review and metaanalysis of HIV prevalence among men in militaries in low income and middle income countries. Sex Transm Infect. 2014;90(5):382-7.

30. Hakre S, Blaylock JM, Dawson P, Beckett C, Garges EC, Michael NL, et al. Knowledge, attitudes, and beliefs about HIV pre-exposure prophylaxis among US Air Force Health Care Providers. Medicine (Baltimore). 2016;95(32):e4511.

31. Galea JT, Kinsler JJ, Salazar X, Lee SJ, Giron M, Sayles JN, et al. Acceptability of pre-exposure prophylaxis as an HIV prevention strategy: barriers and 
facilitators to pre-exposure prophylaxis uptake among at-risk Peruvian

32. Eisingerich AB, Wheelock A, Gomez GB, Garnett GP, Dybul MR, Piot PK. Attitudes and acceptance of oral and parenteral HIV preexposure prophylaxis among potential user groups: a multinational study. PLoS One. 2012;7(1):e28238.

33. Wheelock A, Eisingerich AB, Ananworanich J, Gomez GB, Hallett TB, Dybul $\mathrm{MR}$, et al. Are Thai MSM willing to take PrEP for HIV prevention? An analysis of attitudes, preferences and acceptance. PLoS One. 2013;8(1):e54288.

34. Shrestha R, Karki P, Altice FL, Dubov O, Fraenkel L, Huedo-Medina T, et al. Measuring Acceptability and Preferences for Implementation of Pre-Exposure Prophylaxis (PrEP) Using Conjoint Analysis: An Application to Primary HIV Prevention Among High Risk Drug Users. AIDS and behavior. 2018;22(4):122838.

35. Shrestha R, Altice F, Karki P, Copenhaver M. Developing an Integrated, Brief Biobehavioral HIV Prevention Intervention for High-Risk Drug Users in Treatment: The Process and Outcome of Formative Research. Front Immunol. 2017;8:561.

36. Toubia O, Hauser J, Garcia R. Probabilistic Polyhedral Methods for Adaptive Choice-Based Conjoint Analysis: Theory and Application. Marketing Science. 2007;26(5):596-610.

37. Chapman C, Alford J, Johnson C, Weidemann R, Lahav M. CBC vs. ACBC: comparing results with real product selection. Sawtooth Software Conference Proceedings, Sequim, WA. 2009.

38. Cunningham CE, Deal K, Chen Y. Adaptive choice-based conjoint analysis: a new patient-centered approach to the assessment of health service preferences. Patient. 2010;3(4):257-73.

39. Lowe B, Kroenke K, Grafe K. Detecting and monitoring depression with a twoitem questionnaire (PHQ-2). J Psychosom Res. 2005;58(2):163-71.

40. Wilton J, Kain T, Fowler S, Hart TA, Grennan T, Maxwell J, et al. Use of an HIV-risk screening tool to identify optimal candidates for PrEP scale-up among men who have sex with men in Toronto, Canada: disconnect between objective and subjective HIV risk. J Int AIDS Soc. 2016;19(1):20777.

41. Software S. Lighthouse Studio v9.0 (Formerly SSIWeb). Orem, UT: Sawtooth Software; 2016.

42. Software S. Hosting Security Information 2018 [Available from: https://www.sawtoothsoftware.com/88-services/hosting/1457-hosting-securityinformation.

43. Orme B. Consistency Cutoffs to Identify "Bad" Respondents in CBC, ACBC, and MaxDiff. Sawtooth Software Research Paper Series. 2019.

44. Lenk P, Desarbo W, Green P, Young M. Hierarchical Bayes Conjoint Analysis: Recovery of Partworth Heterogeneity from Reduced Experimental Designs. Marketing Science. 1996;15:173-91.

45. Rao V. Applied Conjoint Analysis2013. 1-389 p.

46. Herrmann A, Gustafsson A, Huber F. Conjoint Measurement: Methods and Applications. University of StGallen. 2007. 
47. Orme B. Getting Started with Conjoint Analysis: Strategies for Product Design and Pricing Research. Second Edition ed. Madison, Wis.: Research Publishers LLC; 2010.

48. Millar BM, Starks TJ, Grov C, Parsons JT. Sexual Risk-Taking in HIV-Negative Gay and Bisexual Men Increases with Depression: Results from a U.S. National Study. AIDS Behav. 2017;21(6):1665-75.

49. Fendrich M, Avci O, Johnson TP, Mackesy-Amiti ME. Depression, substance use and HIV risk in a probability sample of men who have sex with men. Addictive Behaviors. 2013;38(3):1715-8.

50. Parsons JT, Grov C, Golub SA. Sexual Compulsivity, Co-Occurring Psychosocial Health Problems, and HIV Risk Among Gay and Bisexual Men: Further Evidence of a Syndemic. American Journal of Public Health. 2012;102(1):156-62.

51. Gleason JL, Beck KH. Examining Associations Between Relocation, Continuity of Care, and Patient Satisfaction in Military Spouses. Military Medicine. 2017;182(5-6):e1657-e64.

52. Brown RA, Marshall GN, Breslau J, Farris C, Osilla KC, Pincus HA, et al. Access to Behavioral Health Care for Geographically Remote Service Members and Dependents in the U.S. Rand Health Q. 2015;5(1):21-.

53. Blumenthal J, Jain S, Krakower D, Sun X, Young J, Mayer K, et al. Knowledge is Power! Increased Provider Knowledge Scores Regarding Pre-exposure Prophylaxis (PrEP) are Associated with Higher Rates of PrEP Prescription and Future Intent to Prescribe PrEP. AIDS and behavior. 2015;19(5):802-10.

54. Hernandez-Romieu AC, Sullivan PS, Sanchez TH, Kelley CF, Peterson JL, Del Rio $\mathrm{C}$, et al. The comparability of men who have sex with men recruited from venue-time-space sampling and facebook: a cohort study. JMIR Res Protoc. 2014;3(3):e37.

55. Grov C, Westmoreland D, Rendina HJ, Nash D. Seeing Is Believing? Unique Capabilities of Internet-Only Studies as a Tool for Implementation Research on HIV Prevention for Men Who Have Sex With Men: A Review of Studies and Methodological Considerations. J Acquir Immune Defic Syndr. 2019;82 Suppl 3:S253-S60.

56. Whooley MA, Avins AL, Miranda J, Browner WS. Case-finding instruments for depression. Two questions are as good as many. J Gen Intern Med. 1997;12(7):439-45. 
Table 1. Consort diagram for participant enrollment and exclusion, and part-worth utility scores (PWUS) of total sample with omitted responses due to RLH included.

\begin{tabular}{|c|c|c|c|}
\hline \multirow{3}{*}{$\begin{array}{l}\text { Enrollment } \\
1238 \\
\text { completed } \\
\text { survey } \\
\text { responses } \\
\end{array}$} & rclusion & \multicolumn{2}{|c|}{$\begin{array}{l}\text { Total Sample PWUS with omitted } \\
\text { responses due to } \mathrm{RLH}^{3}\end{array}$} \\
\hline & & \multicolumn{2}{|c|}{ Attribute/Levels $\quad$ PWUS } \\
\hline & & \multicolumn{2}{|l|}{ Dosing Method } \\
\hline & \multirow{8}{*}{$\begin{array}{l}\begin{array}{l}\text { Demographics Ineligibility } \\
(n=351)^{1}\end{array} \\
\text { - } \quad \text { Cis-gendered women } \\
\\
(n=139) \\
\text { - } \quad \text { HIV-positive }(n=66) \\
\text { - } \quad \text { Mo MSM activity }(n=72) \\
\text { - Service impossibility } \\
\quad(n=74)\end{array}$} & Daily pill & 10.2 \\
\hline & & PrEP injection & 11.2 \\
\hline & & PrEP implant & -3.6 \\
\hline & & On-demand & 9.1 \\
\hline & & Rectal douche & -26.9 \\
\hline & & Provider Type & \\
\hline & & Military & 3.8 \\
\hline & & Civilian & -3.8 \\
\hline & & PrEP Visit Location & \\
\hline & Data Quality Parameters $(n=458)$ & Smartphone & 3.2 \\
\hline & - Below $95^{\text {th }}$ percentile RLH & On-base & 4.5 \\
\hline & $(n=432)$ & Off-base & -7.8 \\
\hline & time completion $(n=26)$ & Lab Evaluation & \\
\hline & & On-base & 15.0 \\
\hline & & Off-base & -5.9 \\
\hline \multirow{6}{*}{$\begin{array}{l}\mathbf{4 2 9} \text { total } \\
\text { completed } \\
\text { responses } \\
\text { included }\end{array}$} & & Mail-in kit & -9.1 \\
\hline & & Dispensing Venue & \\
\hline & & On-base & 11.2 \\
\hline & & Off-base & -2.0 \\
\hline & & By mail & -9.2 \\
\hline & & $N O N E^{4}$ & -25.2 \\
\hline \multicolumn{4}{|c|}{$\begin{array}{l}\text { Notes: } \\
\text { 1: Inclusion criteria demographics were assessed twice; at consent screen for eligibility, and again after } \\
\text { conjoint experiment. } \\
\text { 2: Omitted responses indicated a service impossibility, such as self-identifying as an Air Force warrant } \\
\text { officer (does not exist) } \\
\text { 3: PWUS calculated using omitted respondents due to RLH cut-off to examine differences in scores. } \\
\text { 4: Increase in NONE utility score (up from -57.7), indicating that including the omitted responses with } \\
\text { low RLH scores into the final sample affects the computation of PrEP participation rates calculated } \\
\text { using the NONE utility score. }\end{array}$} \\
\hline
\end{tabular}




\begin{tabular}{|c|c|c|c|c|c|}
\hline Variable & Frequency & $\%$ & Variable & Frequency & $\%$ \\
\hline Age: Mean ( $\pm S D)$ & $29.9(4.7)$ & & Condom Use with Casual M & le Partner & \\
\hline Gender & & & Every time & 46 & 10.7 \\
\hline Male & 415 & 96.7 & Often & 156 & 36.4 \\
\hline Trans Female & 11 & 2.6 & Sometimes & 127 & 29.6 \\
\hline Trans Male & 3 & 0.7 & Rarely & 66 & 15.4 \\
\hline $\begin{array}{l}\text { Sexual Identity: Mean } \\
( \pm S D)^{a}\end{array}$ & $7.0(2.7)$ & & Never & 10 & 2.3 \\
\hline Race & & & No regular partner & 24 & 5.6 \\
\hline White & 309 & 72.0 & \# of Condom-less Receptive & Anal Sex the & \\
\hline Black & 78 & 18.2 & Past 6 Months & & \\
\hline All Other Race & 42 & 9.8 & None & 69 & 16.1 \\
\hline Ethnicity & & & $\begin{array}{l}\text { About once/month or } \\
\text { less }\end{array}$ & 249 & 58.0 \\
\hline Hispanic & 118 & 27.5 & $\begin{array}{l}\text { About once/week or } \\
\text { more }\end{array}$ & 111 & 25.9 \\
\hline Non-Hispanic & 311 & 72.5 & Comfort Level Discussing Se & $x$ with $P C P$ & \\
\hline Rank & & & $\begin{array}{l}\text { Extremely } \\
\text { Uncomfortable }\end{array}$ & 37 & 8.6 \\
\hline Enlisted & 161 & 37.5 & $\begin{array}{l}\text { Somewhat } \\
\text { Uncomfortable }\end{array}$ & 121 & 28.2 \\
\hline Officer & 199 & 46.4 & Mostly Comfortable & 209 & 48.7 \\
\hline Warrant & 69 & 16.1 & $\begin{array}{l}\text { Extremely } \\
\text { Comfortable }\end{array}$ & 62 & 14.5 \\
\hline Education & & & How Fearful of PCP Judging & You for bein & ASM? \\
\hline High School & 28 & 6.5 & Very Fearful & 62 & 14.5 \\
\hline AD or Some College & 169 & 39.4 & Somewhat Fearful & 144 & 33.6 \\
\hline Bachelor's Degree & 188 & 43.8 & Slightly Fearful & 148 & 34.5 \\
\hline Graduate/Prof Degree & 44 & 10.3 & Not At All Fearful & 75 & 17.5 \\
\hline Military Branch & & & How Fearful of PCP Mistred & ting You for & \\
\hline Air Force & 65 & 15.2 & being MSM? & & \\
\hline Army & 209 & 48.7 & Very Fearful & 79 & 18.4 \\
\hline Coast Guard & 49 & 11.4 & Somewhat Fearful & 115 & 26.8 \\
\hline Marine Corps & 48 & 11.2 & Slightly Fearful & 160 & 37.3 \\
\hline Navy & 58 & 13.5 & Not At All Fearful & 75 & 17.5 \\
\hline Region of Station ${ }^{b}$ & & & Decision Support Autonomy & by $P C P$ & \\
\hline Midwest & 55 & 12.8 & Not Important & 4 & 0.9 \\
\hline Northeast & 79 & 18.4 & Slightly Important & 89 & 20.7 \\
\hline Southeast & 121 & 28.2 & Somewhat Important & 183 & 42.7 \\
\hline Southwest & 40 & 9.3 & Very Important & 153 & 35.7 \\
\hline West & 129 & 30.1 & $\begin{array}{l}\text { Sexual Identity Affirmation } \\
\text { by } P C P\end{array}$ & & \\
\hline Other/OCONUS & 5 & 1.2 & Not Important & 24 & 5.6 \\
\hline Location Type of Station & & & Slightly Important & 130 & 30.3 \\
\hline Remote & 33 & 7.7 & Somewhat Important & 199 & 46.4 \\
\hline Rural & 77 & 17.9 & Very Important & 76 & 17.7 \\
\hline Suburban & 150 & 35.0 & Depression PHQ Screening & & \\
\hline Urban/City & 169 & 39.4 & $>=1$ & 269 & 62.7 \\
\hline $\begin{array}{l}\text { Condom Use with Regular } \\
\text { Male Partner }\end{array}$ & & & $=0$ & 160 & 37.3 \\
\hline Every time & 51 & 11.9 & HIRI-MSM Risk Score ${ }^{d}$ & & \\
\hline Often & 144 & 33.6 & $>=10$ & 383 & 89.3 \\
\hline Sometimes & 111 & 25.9 & $<10$ & 46 & 10.7 \\
\hline Rarely & 68 & 15.9 & & & \\
\hline
\end{tabular}


Table 2. Characteristics of the participants in the aggregate sample $(\mathrm{N}=429)$

\begin{tabular}{|lcc|lcc|}
\hline Variable & Frequency & $\%$ & Variable & Frequency & $\%$ \\
\hline Never & 35 & 8.2 & & & \\
No regular male & & 4.7 & & \\
partner & 20 & & & \\
\hline
\end{tabular}

Notes:

a: 1 -10 range $(1=$ straight/heterosexual, $5=$ bisexual, $10=$ gay/homosexual $)$

b: States within the U.S. Midwest (IA, IL, IN, KS, MI, MN, MO, ND, NE, OH, SD, WI), Northeast

(CT, DC, DE, MA, MD, ME, NH, NJ, NY, PA, RI, VT), Southeast (AL, AR, FL, GA, KY, LA, MS, NC, SC, TN, VA, WV), Southwest (AZ, NM, OK, TX), West (AK, CA, CO, HI, ID, MT, NV, OR, UT, WA, WY), Other/OCONUS (overseas, out of country)

$c$ : Yes/No PHQ2 Version. Scores $>=1$ positive screen(56)

$d$ : $1-47$ range. Scores $>=10$ defined as high risk for $\operatorname{HIV}(40)$

599

600

601

602

603

604

605

606

607 
Table 3. Relative importance scores (RIS) of PrEP attributes for the total sample $(N=429)$ in decreasing order of preference

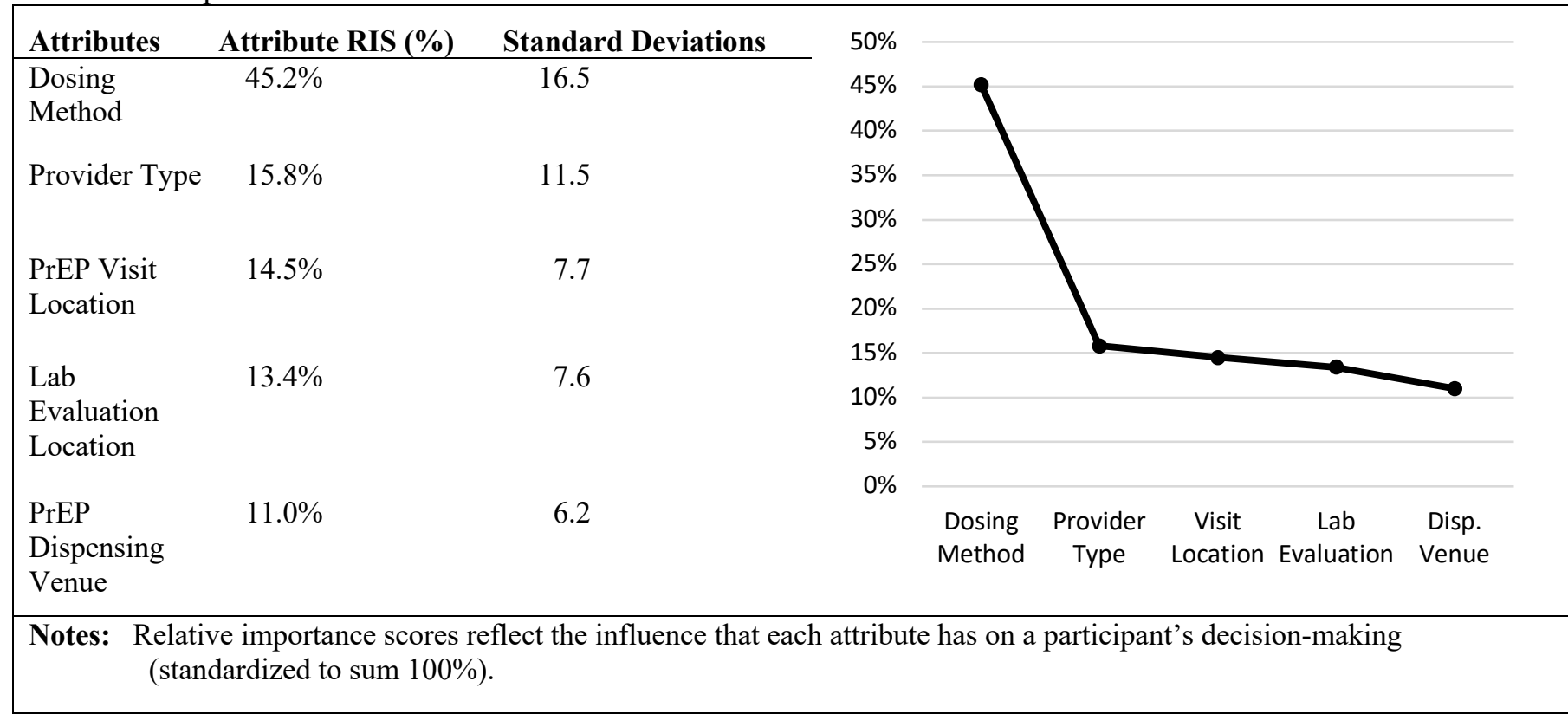


Table 4. Part-worth utilities (zero-centered values) of PrEP program level choices of participants in the aggregate sample $(N=429)$

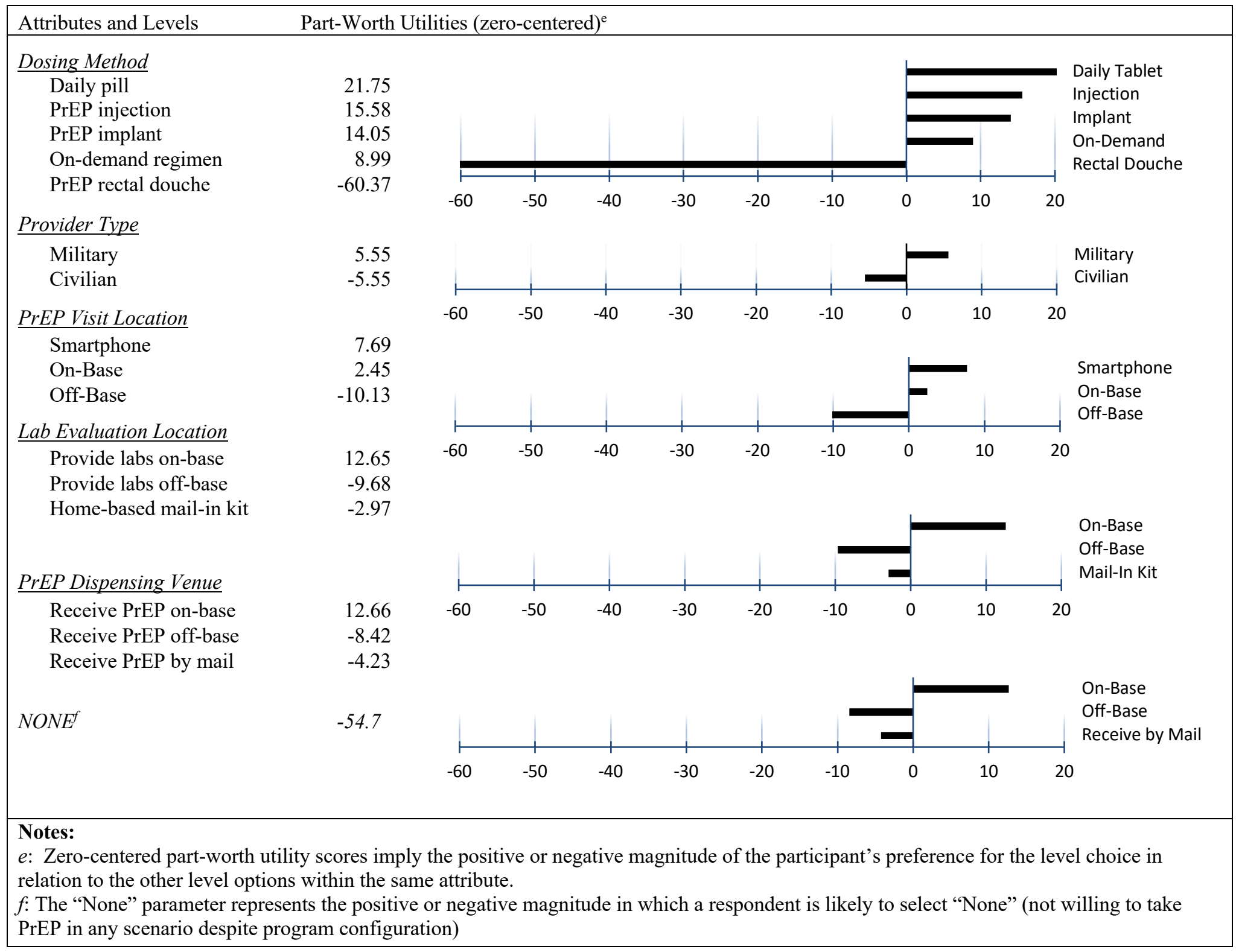


Table 5. Individual Program Preferences. Acceptability (mean) of individual PrEP scenarios with different attributes among participants $(N=429)$.*

\begin{tabular}{|c|c|c|c|c|c|c|}
\hline \multicolumn{7}{|c|}{ PrEP Attributes \& Levels } \\
\hline PrEP Scenario & $\begin{array}{c}\text { Participation } \\
\text { Interest } \% \\
\end{array}$ & Dosing Method & $\begin{array}{l}\text { Provider } \\
\text { Type }\end{array}$ & Visit Location & $\begin{array}{l}\text { Lab } \\
\text { Evaluation }\end{array}$ & $\begin{array}{l}\text { Dispensing } \\
\text { Venue }\end{array}$ \\
\hline 1: Standard Military Daily Pill & $66.4 \%$ & Daily Pill & Military & On-base & On-base & On-base \\
\hline 2: Standard Military + Smartphone & $69.6 \%$ & Daily Pill & Military & Smartphone & On-base & On-base \\
\hline 3: Best Case Military On-Demand & $67.6 \%$ & On-Demand & Military & Smartphone & On-base & On-base \\
\hline 4: Military Home-Based PrEP & $65.2 \%$ & Daily Pill & Military & Smartphone & Home kit & Mail Delivery \\
\hline 5: Standard Civilian Daily Pill & $57.7 \%$ & Daily Pill & Civilian & Off-base & Off-base & Off-base \\
\hline 6: Best Case Military Injection & $69.6 \%$ & Injection & Military & Smartphone & On-base & On-base \\
\hline 7: Best Case Military Implant & $68.5 \%$ & PrEP Implant & Military & Smartphone & On-base & On-base \\
\hline 8: Best Case Military Rectal Douche & $51.6 \%$ & Rectal Douche & Military & Smartphone & On-base & On-base \\
\hline $\begin{array}{r}70 \% \\
60 \% \\
50 \% \\
40 \% \\
30 \% \\
20 \% \\
10 \% \\
0 \%\end{array}$ & & & & & & \\
\hline 2. Std Mil + SP & 3. BC Mil OD & $\begin{array}{l}\text { 4. Mil Dist-B DT } \\
\text { — Participation }\end{array}$ & $\begin{array}{l}\text { td Civ DT } \\
\%\end{array}$ & 6. BC Mil Inj & 7. BC Mil Imp & 8. BC Mil RD \\
\hline \multicolumn{7}{|c|}{$\begin{array}{l}\text { Notes: } \\
\text { *1: Standard (Std) Military (Mil) Daily Pill (DP), 2: Standard Military + Smartphone (SP), 3: Standard Civilian (Civ) Daily Pill, 4: Best } \\
\text { Case (BC) Military On-Demand (OD), 5: Military Home-Based (Home B) PrEP, 6: Best Case Military Injection (Inj), 7: Best Case } \\
\text { Military Implant (Imp), 8: Best Case Military Rectal Douche (RD) }\end{array}$} \\
\hline
\end{tabular}

